DOI: 10.12731/wsd-2017-4-2-32-40

УДК 616

\title{
КЛИНИЧЕСКИЕ И ИММУНО-МЕТАБОЛИЧЕСКИЕ ОСОБЕННОСТИ ТЕЧЕНИЯ ПЕРВИЧНОЙ АТАКИ ОСТРОГО ЛИМФОБЛАСТНОГО ЛЕЙКОЗА
}

\author{
Смирнова О.В., Манчук В.Т.
}

Авторами изучены особенности клинического состояния, клеточного, гуморального звеньев иммунитета и метаболизма лимфоцитов у больных острым лимфобластным лейкозом в дебюте заболевания, при первичной атаке. Заболевание чаще начиналось с появления комбинированных симптомов в клинической картине. Лихорадка, слабость, снижение работоспособности, головокружения, сопутствующий инфекционный процесс регистрировались у большинства больных. Снижение Т-лимфоцитов и уменьшение величины отношения $C D 4^{+} \kappa C D 8^{+}$способствовало появлению дебюта ОЛЛ и развитию Т-клеточного иммунодефицита. Изменялась метаболомика энергетических, пластических прочессов в лимфоцитах. Авторами предложена собственная иммунометаболическая конщепция возникновения заболевания.

Ключевые слова: острый лимфобластный лейкоз; первичная атака; лимфочит; метаболизм; иммунитет.

\section{CLINICAL AND IMMUNO-METABOLIC PECULIARITIES OF THE PRIMARY ATTACK OF ACUTE LYMPHOBLASTIC LEUKEMIA}

\section{Smirnova O.V., Manchuk V.T.}

The authors studied the characteristics of the clinical condition, cellular, humoral immunity and metabolism of lymphocytes in patients with acute lymphoblastic leukemia at the onset of the disease, with the primary attack. The disease usually begins with the combined symptoms appearance in the clinical picture. Fever, fatigue, decreased performance, dizziness, the accompanying infection process were recorded in most patients. Reduction of T-lymphocytes and a decrease in the ratio of $C D 4^{+}$to $C D 8^{+}$contributed to the debut appear- 
ance of ALL and T-cell immunodeficiency development. Changed metabolomics of energy, plastic processes in lymphocytes. The authors proposed an immunometabolic own concept of the disease.

Keywords: acute lymphoblastic leukemia; primary attack; lymphocyte; metabolism; immunity.

Острые лейкозы (ОЛ) - гемобластозы, субстратом опухоли которых являются бластные клетки, с нарушенными пролиферацией, дифференцировкой и апоптозом, способные замещать все нормальные ростки кроветворения в костном мозге и вызывать лейкемическую инфильтрацию периферических тканей и органов. При острых лейкозах происходит мутация стволовой гемопоэтической клетки. Иммунофенотипические особенности бластных клеток влияют не только на клиническое течение заболевания и терапию, но и определяют эффективность лечения и прогноз острых лейкозов (ОЛ) $[1,2]$. ОЛ занимают лидирующие места по частоте встречаемости среди всех гемобластозов человека [1]. Ежегодно регистрируется 5 новых случаев ОЛ на 100000 населения, при этом две трети больных взрослые люди. Соотношение острых миелоидных лейкозов (ОМЛ) к острым лимфоидным лейкозам составляет 6:1. У пациентов в возрасте 40 лет и старше $80 \%$ составляют ОМЛ, а у детей - острый лимфобластный лейкоз (ОЛЛ). У взрослых пациентов ОЛЛ встречается редко, и прогноз его неблагоприятный $[1,2]$.

В связи с этим целью настоящего исследования явилось изучение особенностей клинической картины, иммунопатогенеза у больных ОЛЛ на стадии первичной атаки с выявлением особенностей функционирования метаболических ферментов лимфоцитов.

\section{Материалы и методы}

Всего в исследование были отобраны 73 больных ОЛЛ, в стадии первичной атаки заболевание диагностировалось у 25 больных (ВО3, 1999). Первичная атака ОЛ характеризуется значительным угнетением нормального кроветворения, обусловленным лейкемической инфильтрацией костного мозга бластами, с развитием анемических, геморрагических и инфекционных осложнений. В миелограмме обнаруживается более $25 \%$ бластов $[1,2]$.

Всего в исследование было включено 10 мужчин (40\%) и 15 женщин

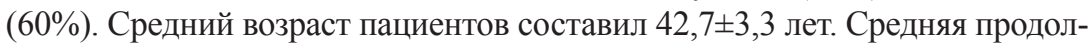

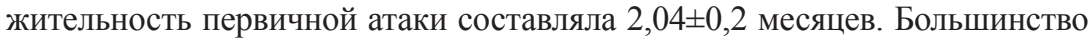


больных (96\%) выписались из стационара после проведенного лечения. Один больной умер при проведении терапии от массивного кровотечения.

У большинства больных (85\%) ОЛЛ в миелограмме обнаруживался тотальный бластоз (средние показатели бластов 93,0土3,2\%). Контрольная группа состояла из 125 практически здоровых добровольцев аналогичные по возрасту с группой изучения.

Оценку клеточного звена иммунитета проводили с помощью метода непрямой иммунофлуоресценции с использованием моноклональных антител к CD3, CD4, CD8, CD16, CD19, HLA-DR. Для дополнительной характеристики Т-клеточного звена иммунной системы вычисляли $\mathrm{CD}^{+} /$ $\mathrm{CD} 8^{+}$отношение. Концентрацию иммуноглобулинов класса $\mathrm{A}, \mathrm{M}$ и $\mathrm{G}$ в сыворотке крови определяли иммуноферментным методом, используя тест-системы $3 \mathrm{AO}$ «Вектор-Бест».

Биолюминесцентное определение активности НАД(Ф)-зависимых дегидрогеназ проводили по ранее разработанным методикам [3]. Данным методом определялась активность следующих ферментов: глюко3о-6-фосфатдегидрогеназы (ГбФДГ), глицерол-3-фосфатдегидрогеназы (ГЗФДГ), малик-фермента (НАДФМДГ), НАД- и НАДН-зависимой реакции лактатдегидрогеназы (ЛДГ и НАДН-ЛДГ), НАД- и НАДН-зависимой реакции малатдегидрогеназы (МДГ и НАДН-МДГ), НАДФ- и НАДФН-зависимой глутаматдегидрогеназы (НАДФГДГ и НАДФН-ГДГ), НАД- и НАДН-зависимой глутаматдегидрогеназы (НАДГДГ и НАДНГДГ), НАД- и НАДФ-зависимых изоцитратдегидрогеназ (НАДИЦДГ и НАДФИЦДГ, соответственно) и глутатионредуктазы (ГР). Активность дегидрогеназ в лимфоцитах крови выражали в ферментативных единицах $\left(1 \mathrm{E}=1\right.$ мкмоль/мин) на $10^{4}$ клеток. Взятие крови осуществлялось при поступлении больного в гематологическое отделение до начала патогенетической терапии.

По результатам исследования была сформирована база данных в электронных таблицах MS Excel 2000, на основе которой производился статистический анализ методами описательной статистики с t-критерием Стьюдента, непараметрическим с использованием точных критериев Манна-Уитни с помощью пакетов прикладных программ Statistica 7.0 (StatSoft Inc., 2004).

\section{Результаты и их обсуждение}

При ОЛЛ мутация происходит в клетке предшественницы лимфопоэза, а опухолевой клон представлен в значительной мере лимфобластами 
$[1,2,4]$. При поступлении у $20 \%$ больных выявлялись симптомы анемии, у $4 \%$ - гиперплазия лимфатических узлов, печени, селезенки, у $24 \%$ - инфекционные осложнения и у $52 \%$ - сочетанные клинические признаки

У большинства больных (96\%) при поступлении выявлялась лихорадка более 38 градусов. У всех больных выявлялись симптомы опухолевой интоксикации.

У 40\% больных обнаруживался геморрагический синдром: у 16\% пациентов - в виде подкожных кровоизлияний, у $8 \%$ - десневые кровотечения, у $12 \%$ больных - кровотечения из носа и у $4 \%$ пациентов - маточное кровотечение.

Бактериальные и вирусные осложнения выявлялись при поступлении у $68 \%$ больных ОЛЛ. Генерализованная лимфоаденопатия обнаруживалась у $32 \%$ больных, у $12 \%$ - гипертрофические изменения десен. Гепатомегалия выявлялась у $48 \%$, спленомегалия - у $24 \%$ пациентов.

Сопутствующие симптомы в виде одышки при незначительной физической нагрузке диагностировались у $32 \%$ больных, отеки нижних конечностей - у $20 \%$, нарушения ритма и сердцебиения - у $20 \%$ пациентов.

Ответная реакция на химиотерапию была у всех больных ОЛЛ. Постхимиотерапевтические осложнения в виде панцитопении появились у $60 \%$ больных, агранулоцитоз - у 92\%. У 64\% больных развились внутрибольничные инфекционные осложнения, у $32 \%$ - геморрагические проявления, у $92 \%$ пациентов - симптомы анемии средней и тяжелой степени тяжести.

Гемобластозы - являются иммуноопосредованными заболеваниями, тяжесть клинического состояния во многом определяется изменениями иммунной системы больного, вызванными как самим заболеванием, так и проводимым патогенетическим лечением. Иммунные нарушения встречаются как при острых, так и хронических лейкозах $[5,6]$. При исследовании состояния клеточного звена иммунитета у лиц контрольной группы и больных ОЛЛ установлено, что на стадии первичной атаке у больных выявляется лимфоцитоз и снижаются относительные и абсолютные показатели pan-маркеров Т-лимфоцитов (табл.1). Снижение соотношения $\mathrm{CD} 4^{+}$- к $\mathrm{CD} 8^{+}$-клеткам свидетельствует о нарушении баланса между Т-хелперами и цитотоксическими лимфоцитами. Уменьшение количества Т-хелперов способствует неэффективности клеточного и гуморального иммунного ответа при остром лимфобластном лейкозе в будущем. У больных ОЛЛ на стадии первичной атаки нарушены процессы активации лимфоцитов и выявляется большое количество Т-активированных клеток (повышена величина индекса активации Т-лимфоцитов). 
При изучении состояния гуморального звена иммунитета нами выявлено, что у больных ОЛЛ на стадии первичной атаки содержание иммуноглобулинов основных классов и величина уровней относительного синтеза иммуноглобулинов не изменена и не отличается от нормального контрольного диапазона (табл. 1). Отсутствие изменений в гуморальном звене иммунитета на данной стадии указывает на то, что опухолевый процесс в начале своего развития, и в первую очередь страдает клеточное звено иммунитета.

Таблийа 1.

Показатели иммунного статуса у больных ОЛЛ на стадии первичной атаки $\left(\mathrm{Me}, \mathrm{C}_{25}-\mathrm{C}_{75}\right)$

\begin{tabular}{|c|c|c|c|c|}
\hline \multirow[t]{2}{*}{ Показатели } & \multicolumn{2}{|c|}{$\begin{array}{c}\text { Контроль, } \mathrm{N}=118 \\
1\end{array}$} & \multicolumn{2}{|c|}{$\begin{array}{c}\text { Атака, } \mathrm{N}=25 \\
2\end{array}$} \\
\hline & $\mathrm{Me}$ & $\mathrm{C}_{25}-\mathrm{C}_{75}$ & $\mathrm{Me}$ & $\mathrm{C}_{25}-\mathrm{C}_{75}$ \\
\hline Лейкоциты, (109/л) & 5,73 & $4,85-7,75$ & 6,70 & $3,60-12,00$ \\
\hline Лимфоциты, (\%) & 38,0 & $31,0-45,0$ & 37,0 & $21,0-70,0$ \\
\hline \multirow{2}{*}{$\mathrm{CD}^{+},(\%)$} & 67,0 & $60,0-72,0$ & 59,0 & $40,0-70,0$ \\
\hline & & & \multicolumn{2}{|c|}{$\mathrm{P}_{2-1}<0,05$} \\
\hline $\mathrm{CD}^{+},(\%)$ & 44,0 & $34,0-49,0$ & 31,0 & $27,0-45,0$ \\
\hline $\mathrm{CD}^{+},(\%)$ & 27,0 & $20,0-34,0$ & 27,0 & $16,0-38,0$ \\
\hline $\mathrm{CD} 16^{+},(\%)$ & 20,0 & $17,0-23,0$ & 20,0 & $8,0-23,0$ \\
\hline $\mathrm{CD}^{2} 9^{+},(\%)$ & 13,5 & $9,0-16,0$ & 12,0 & $4,0-22,0$ \\
\hline HLA-DR ${ }^{+},(\%)$ & 15,0 & $12,0-20,0$ & 11,5 & $7,5-25,5$ \\
\hline \multirow{2}{*}{$\mathrm{CD}^{+} / \mathrm{CD}^{+}$} & 1,52 & $1,13-1,95$ & 1,30 & $0,90-1,50$ \\
\hline & & & \multicolumn{2}{|c|}{$\mathrm{P}_{2-1}<0,05$} \\
\hline $\operatorname{IgA},(г / л)$ & 1,91 & $1,33-3,20$ & 1,60 & $1,15-2,80$ \\
\hline $\operatorname{IgM},(г / л)$ & 1,20 & $0,50-1,80$ & 1,10 & $0,72-2,13$ \\
\hline $\operatorname{IgG},(г / л)$ & 10,30 & $8,18-14,12$ & 11,00 & $6,07-26,00$ \\
\hline
\end{tabular}

Примечание: $\mathrm{p}_{2-1}$ - статистически достоверные различия с показателями контрольной группы.

При исследовании корреляционной взаимосвязи между показателями иммунного статуса и содержанием бластных клеток в костном мозге в зависимости от стадии заболевания обнаружена единственная статистически достоверная отрицательная взаимосвязь средней силы между относительным количеством рап-маркеров Т-лимфоцитов и содержанием бластов $(\mathrm{r}=-0,47, \mathrm{p}<0,05)$. Учитывая, что опухолевым субстратом ОЛЛ являются лимфобласты, способные к миграции и замещению нормальных ростков, их содержание безусловно влияет на количество и функционирование Т-лимфоцитов. 
С помощью метода нейропредикторного классификатора была исследована информативность показателей иммунного статуса в определении содержания бластных клеток в костном мозге у больных на стадии первичной атаки ОЛЛ. Установлено, что наиболее значимыми показателями системной модели являются уровень относительного содержания pan-маркеров Т-лимфоцитов, уровень относительного синтеза IgM, абсолютное количество HLA-DR ${ }^{+}$, pan-маркеров Т-лимфоцитов и CD16 ${ }^{+}$-клеток. Выявленные информативные показатели свидетельствуют о поражении всех звеньев иммунной системы при данном гемобластозе.

При изучении состояния метаболического статуса лимфоцитов крови у больных ОЛЛ на стадии первичной атаки установлено, что активность ГЗФДГ снижена относительно контрольного диапазона на стадии первичной атаки (табл. 2), следовательно, выявляется уменьшенный уровень переноса продуктов липидного катаболизма на восстановительно-окислительные реакции гликолиза. В лимфоцитах крови больных снижена активность ЛДГ (уменьшается уровень гликолиза) и МДГ, НАДГДГ, что приводит к нарушению взаимосвязей между реакциями цикла Кребса и процессами аминокислотного обмена. В то же время, активность НАДИЦДГ в лимфоцитах крови у больных лиц на стадии атаки снижена относительно контрольного диапазона, что приводит к снижению интенсивности субстратного потока по лимонному циклу.

Исследование активности НАДФ-зависимых дегидрогеназ в лимфоцитах крови позволило установить, что у больных ОЛЛ в дебюте заболевания при сравнении с контрольным диапазоном снижен уровень НАДФИЦДГ, что обуславливает недостаточность метаболических биохимических реакций в митохондриях. При исследовании активности НАДН-зависимых реакций оксидоредуктаз в лимфоцитах крови установлено снижение уровня НАДН-ЛДГ относительно контрольного диапазона, что приводит к ингибированию гликолиза на терминальных реакциях.

\section{Заключение}

У больных ОЛЛ на стадии первичной атаки чаще выявлялась при поступлении клиническая картина комбинированных симптомов. У большинства больных при поступлении выявлялись лихорадка, признаки опухолевой интоксикации, сопутствующие инфекционные осложнения. У всех больных была получена ответная реакция на проводимую терапию. При этом у большинства больных развились осложнения в виде агранулоцитоза и панцитопении с анемическими, инфекционными и геморрагическими симптомами. 
Таблица 2.

Показатели метаболического статуса в лимфоцитах в крови у больных ОЛЛ на стадии первичной атаки (Me, $\left.\mathrm{C}_{25}-\mathrm{C}_{75}\right)$

\begin{tabular}{|c|c|c|c|c|}
\hline \multirow[t]{2}{*}{ Показатели } & \multicolumn{2}{|c|}{$\begin{array}{c}\text { Контроль, } \mathrm{N}=118 \\
1\end{array}$} & \multicolumn{2}{|c|}{$\begin{array}{c}\text { Атака, } \mathrm{N}=25 \\
2\end{array}$} \\
\hline & $\mathrm{Me}$ & $\mathrm{C}_{25}-\mathrm{C}_{75}$ & $\mathrm{Me}$ & $\mathrm{C}_{25}-\mathrm{C}_{75}$ \\
\hline ГбФДГ & 4,32 & $0,90-13,87$ & 1,88 & $0,00-21,74$ \\
\hline \multirow{2}{*}{ гЗФДГ } & 0,63 & $0,00-1,96$ & 0,00 & $0,00-0,60$ \\
\hline & & & \multicolumn{2}{|c|}{$P_{2-1}<0,05$} \\
\hline \multirow{2}{*}{ лдГ } & 38,43 & $14,85-98,98$ & 3,87 & $0,30-14,96$ \\
\hline & & & \multicolumn{2}{|c|}{$\mathrm{P}_{2-1}<0,001$} \\
\hline НАДФМДГ & 2,84 & $0,64-12,75$ & 1,15 & $0,00-5,78$ \\
\hline НАДФГДГ & 0,59 & $0,00-2,56$ & 0,18 & $0,00-2,38$ \\
\hline \multirow{2}{*}{ НАДФИЦДГ } & 33,33 & $14,70-63,63$ & 0,45 & $0,16-1,27$ \\
\hline & & & \multicolumn{2}{|c|}{$\mathrm{P}_{2-1}<0,001$} \\
\hline \multirow{2}{*}{ мДГ } & 70,43 & $17,99-144,34$ & 15,25 & $6,24-30,00$ \\
\hline & & & \multicolumn{2}{|c|}{$\mathrm{P}_{2-1}<0,01$} \\
\hline \multirow{2}{*}{ НАДГДГ } & 5,64 & $0,47-16,76$ & 1,70 & $0,50-5,05$ \\
\hline & & & \multicolumn{2}{|c|}{$P_{2-1}<0,05$} \\
\hline \multirow{2}{*}{ НАДИЦДГ } & 4,05 & $1,00-12,93$ & 0,01 & $0,00-0,49$ \\
\hline & & & \multicolumn{2}{|c|}{$\mathrm{P}_{2-1}<0,001$} \\
\hline \multirow{2}{*}{ НАДН-ЛДГ } & 72,87 & $8,56-196,34$ & 0,00 & $0,00-118,48$ \\
\hline & & & \multicolumn{2}{|c|}{$\mathrm{P}_{2}<0,05$} \\
\hline НАДН-МДГ & 128,37 & $35,45-357,11$ & 141,42 & $32,00-228,54$ \\
\hline ГР & 19,64 & $1,67-113,62$ & 8,54 & $1,24-42,20$ \\
\hline НАДН-ГДГ & 49,94 & $13,93-83,36$ & 22,38 & $1,68-48,42$ \\
\hline НАДФН-ГДГ & 52,87 & $29,59-84,88$ & 42,37 & $12,26-107,15$ \\
\hline
\end{tabular}

Примечание: то же, что и для табл. 1

У больных ОЛЛ на стадии первичной атаки развивался Т-клеточный иммунодефицит, при этом важнейшими патогенетическими звеньями в прогрессировании явились снижение рап-маркеров Т-лимфоцитов и нарушения соотношения Т-хелперов к цитотоксическим лимфоцитам.

При исследовании состояния метаболического статуса лимфоцитов крови у больных ОЛЛ на стадии первичной атаки наблюдалось выраженное уменьшение интенсивности внутриклеточных метаболических процессов лимфоцитов, снижались транспорт в митохондриальном компартменте, гликолиз (особенно терминальные реакции), метаболизм лимонной кислоты. Важной особенностью первичной атаки ОЛЛ являлись нормальное функционирование глутатионового звена антиоксидантной защиты, при уменьшении внутриклеточного липидного катаболизма и увеличении переаминирования. 


\section{Сиисок литературы}

1. Воробьев А.И. Руководство по гематологии. М.: Ньюдиамед, 2002.

2. Воробьев А.И. Руководство по гематологии. М.: Ньюдиамед, 2003.

3. Савченко А.А., Сунцова Л.Н. Высокочувствительное определение активности дегидрогеназ в лимфоцитах периферической крови биолюминесцентным методом. Лаб. дело. 1989; 11: 23-25.

4. Савченко В.Г., Паровичникова Е.Н., Исаев В.Г. и др. Лечение острых лимфобластных лейкозов взрослых как нерешенная проблема. Терапевт. арх. 2001; 7: 6-15.

5. Смирнова О.В. Хронический миелолейкоз - клинические и иммунологические особенности у взрослых больных. Бюллетень Восточно-сибирского научного центра Сибирского отделения Российской академии медицинских наук. 2012; 3 (85): 185-189.

6. Смирнова О.В., Манчук В.Т. Особенности прогнозирования возникновения инфекционных осложнений после проведения химиотерапии у больных острыми лейкозами. Медицинская иммунология. 2012; 14, 4-5: 403-408.

\section{References}

1. Vorob'ev A.I. Rukovodstvo po gematologii [Manual of Hematology]. M.: N'yudiamed. 2002.

2. Vorob'ev A.I. Rukovodstvo po gematologii [Manual of Hematology]. M.: N'yudiamed. 2003.

3. Savchenko A.A., Suntsova L.N. Vysokochuvstvitel'noe opredelenie aktivnosti degidrogenaz $\mathrm{v}$ limfotsitakh perifericheskoy krovi biolyuminestsentnym metodom [Highly sensitive determination of dehydrogenase activity in peripheral blood lymphocytes bioluminescent method]. Lab. Delo [Lab. Business]. 1989. 11: 23-25.

4. Savchenko V.G., Parovichnikova E.N., Isaev V.G. et al. Lechenie ostrykh limfoblastnykh leykozov vzroslykh kak nereshennaya problema [Treatment of adult acute lymphoblastic leukemia as an unsolved problem]. Terapevt. Arkh [The therapist. Arch]. 2001. 7: 6-15.

5. Smirnova O.V. Khronicheskiy mieloleykoz - klinicheskie i immunologicheskie osobennosti u vzroslykh bol'nykh [Chronic myelogenous leukemia - clinical and immunological features of adult patients]. Byulleten'Vostochno-sibirskogo nauchnogo tsentra Sibirskogo otdeleniya Rossiyskoy akademii meditsinskikh nauk [Bulletin of the East-Siberian Scientific Center of the Siberian Branch of the Russian Academy of Medical Sciences]. 2012.3 (85): 185-189. 
6. Smirnova O.V., Manchuk V.T. Osobennosti prognozirovaniya vozniknoveniya infektsionnykh oslozhneniy posle provedeniya khimioterapii u bol'nykh ostrymi leykozami [Features predicting the occurrence of infectious complications after chemotherapy in patients with acute leukemia]. Meditsinskaya immunologiya [Medical Immunology]. 2012; 14, 4-5: 403-408.

\section{ДАННЫЕ ОБ АВТОРАХ}

Смирнова Ольга Валентиновна, д.м.н., профессор, заведующая лабораторией клинической патофизиологии

Федеральное государственное бюджетное научное учреждение "Федеральный исследовательский иентр «Красноярский научный иентр Сибирского отделения Российской академии наук» «Научно-исследовательский институт медицинских проблем Севера» ул. Партизана Железняка, 32, г. Красноярск, 660022, Российская Федераичия ovsmirnova71@mail.ru

Манчук Валерий Тимофеевич, член-корреспондент РАН, профессор, доктор медицинских наук, руководитель научного направления Федеральное государственное бюджетное научное учреждение "Федеральный исследовательский иентр «Красноярский научный иентр Сибирского отделения Российской академии наук» «Научно-исследовательский институт медицинских проблем Севера» ул. Партизана Железняка, 32, г. Красноярск, 660022, Российская Федераиия

\section{DATA ABOUT THE AUTHORS}

Smirnova Olga Valentinovna, MD, Professor, Head of the Laboratory of Clinical Pathophysiology

Scientific Research Institute of Medical Problems of the North 3g, Partizan Zheleznyaka Str., Krasnoyarsk, 660022, Russian Federation ovsmirnova71@mail.ru

Manchuk Valery Timofeevich, Corresponding Member of the Russian Academy of Sciences, Professor, Doctor of Medical Sciences, Head of Research

Scientific Research Institute of Medical Problems of the North 3g, Partizan Zheleznyaka Str., Krasnoyarsk, 660022, Russian Federation 